\title{
Inducible Treg cell populations as cell based- therapy for rheumatoid arthritis
}

\author{
Delphine Martire 1 , Julie Quentin ${ }^{1}$, Anne-Laure Mausset-Bonnefont ${ }^{1}$, Hélène Asnagli², Nathalie Belmonte², \\ Arnaud Foussat ${ }^{2}$, Christian Jorgensen ${ }^{1}$, Pascale Louis-Plence ${ }^{1 *}$ \\ From 7th European Workshop on Immune-Mediated Inflammatory Diseases \\ Noordwijk aan Zee, the Netherlands. 28-30 November 2012
}

\section{Background}

Adoptive cell transfer of Treg cells is a promising approach to restore tolerance in autoimmune disease.

However the various type of Tregs, their doses of injection and their in vivo-suppressive mechanism need to be precisely define to clearly establish which Tregs will be able to dampen efficiently the immune response in the various settings.

In our study, we compared the therapeutic potential of induced $\mathrm{CD} 25^{+} \mathrm{FoxP}^{+}$and two IL10-secreting Tregs: Tr1 and CD49b-induced Tregs.

\section{Materials and methods}

CD49b Treg cells were generated in naive mice following repetitive injections of $\mathrm{iDC}$. The purification was based on the negative selection of $\mathrm{CD} 4 \mathrm{~T}$ cells isolated from the spleen and liver of the iDC-vaccinated mice.

Cell sorting experiments were realized to obtain $98 \%$ pure $\mathrm{CD} 49 \mathrm{~b}^{+} \mathrm{T}$ or $\mathrm{CD} 25^{+}$cells. Collagen type II (bCII) specific Tr1 clones were obtained from TCR transgenic mice and expanded in vitro. Selected clones showed in vitro antigen specificity, $\operatorname{Tr} 1$ cytokine profile and IL10and TGF $\beta$-dependent suppressive activity.

\section{Results}

Several doses of CD49b or $\operatorname{Tr} 1$ cells were injected i.v. at day 28 in established collagen-induced arthritis. Clinical signs of arthritis were scored, as well as biological parameters such as the level of anti-bCII antibodies in sera and the cytokine profile of bCII specific $\mathrm{T}$ cells.

We defined for both Treg cell populations the dose effect in curative settings experiments. One single dose of $3 \times 10^{6}$ or $1 \times 10^{6}$ of $\operatorname{Tr} 1$ cell administration could reduce the incidence and severity of CIA. Interestingly, higher dose of $10 \mathrm{M}$ of $\operatorname{Tr} 1$ cells did not improve the disease. In the same manner, the dose of $10^{5} \mathrm{CD} 4 \mathrm{CD} 49 \mathrm{~b}^{+}$or $\mathrm{CD} 25^{+}$ cells reverse clinical symptom with a lack of efficacy of higher doses. The cytokinic profile of the $\operatorname{Tr} 1$ cells was also investigated in inflammatory settings as well as the impact of the various Treg cells on the proliferation of effector cells in vivo.

\section{Conclusions}

Our results suggest that even if the Treg cells present some similarities, we need to precisely define the dose and type of Treg that will be efficient in each experimental setting.

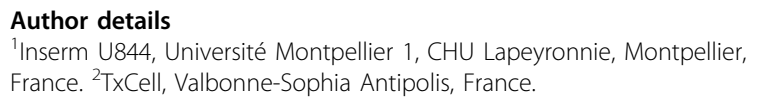

Published: 28 November 2012

doi:10.1186/1479-5876-10-S3-P55

Cite this article as: Martire et al.: Inducible Treg cell populations as cell based-therapy for rheumatoid arthritis. Journal of Translational Medicine 2012 10(Suppl 3):P55. 